\title{
Configuring Service Operations in Accordance With Customer Needs and Preferences
}

\author{
Rohit Verma \\ DePaul University \\ Gary M. Thompson \\ Cornell University \\ Jordan J. Louviere \\ University of Sydney
}

\begin{abstract}
This study presents an approach for effective service operations management by integrating market-based objectives and operating decisions of managers. This approach is based on constructs from operations management, econometrics, and marketing and can be used by managers to make better decisions about product/service design and positioning services according to market needs. Empirical data for this study were collected from the pizza delivery industry in a large metropolitan area in the western United States. Pizza delivery profiles were experimentally designed based on seven attributes: promised delivery time, actual delivery time, pizza variety, pizza temperature, money-back guarantee, price, and discount. An econometric procedure known as probabilistic discrete choice analysis was used to identify the customer pizza choice patterns and managers' perceptions of customer choice patterns. The results show how customers trade off among different attributes when choosing a pizza delivery company. Managers can use this information to position their operations according to customer needs.
\end{abstract}

\section{Introduction}

As the field of service operations management moves beyond the "exploratory" research stage, a number of scholars have emphasized that an integration of operations and marketing perspectives are essential for design and management of high-performing services (Chase 1996; Karmarkar 1996; Karmarkar and Pitbladdo 1995). For example, Bowen and Cummings (1990), Lovelock (1992), and Sullivan (1981) advocate an integrated approach to service management and suggest that managers can improve service operations by their awareness and use of marketing constructs and techniques. Similarly, Griffen and Hauser (1993) illustrate the usefulness of integrating the "voice of the customer" into the design of service businesses. Davidow and Uttal (1989) suggest using market segmentation analysis to determine service strategies for different segments of customers. Likewise, Heskett's (1987) "strategic service vision" involves identification of target market segments, development of a service concept to address targeted customers' needs, codification of an operating strategy to support the service concept, and design of a service delivery system to support the operating strategy. Several researchers also have shown the importance of linking customer satisfaction measures to customer 
preferences, market shares, and the financial performance of service firms (Anderson, Fornell, and Rust 1997; Kordupleski, Rust, and Zahorik 1993; Rust, Zahorik, andKeiningham 1995; Youngdahl andKellogg 1997). Common sense also tells us that to increase market share/ profit in highly competitive business environments, firms must design service facilities and service characteristics to closely accord with customer preferences.

Incorporating customer preferences and choices into managerial decisions is important to all service businesses because customers generally evaluate offerings on more than one criterion such as price, quality, and delivery speed for delivered pizza (Green and Krieger 1996; Louviere and Timmermans 1990; McFadden 1986). Yet, it probably is unrealistic to think that a typical service provider can excel on all competitive dimensions simultaneously. Hence, understanding how customers integrate information about (and trade off among) different service attributes can help firms effectively position their service offerings.

To be competitive, companies also must support customer preferences with effective process design. A product-service package designed to appeal to the needs and desires of particular segments of customers may deliver less than the firm expects without the ability to efficiently manage, control, and improve back-end processes. Thus, customer preference information must be translated and fed back into design and day-to-day management of service processes.

In this article, we provide a way in which to estimate customers' preferences in service businesses and guidelines for incorporating the preference information into the design and management of service processes. The approach described in this article is known as probabilistic discrete choice analysis (DCA), which has been used successfully in many applied projects in marketing, transportation, natural resource economics, and other social sciences. When properly designed and applied, DCA can have a significant impact on service design and management.

The rest of this article is divided into three sections. First, we present the theoretical background of DCA and describe how it differs from a popular market research method known as conjoint analysis. Second, we provide guidelines for designing and conducting a DCA study that include an empirical illustration focusing on the pizza delivery industry. Finally, we provide examples of various types of analyses that can be conducted to link customer preferences with service design and day-to-day management decisions.

\section{Discrete Choice Analysis: Background Information}

Probabilistic DCA provides a systematic way in which to identify the implied relative weights and attribute tradeoffs revealed by the choices of decision makers (e.g., a customer, a manager). DCA has been used to model choice behavior in many business and social science fields, and introductions to and extensions of DCA can be found in sources such as Ben-Akiva and Lerman (1991), Gensch and Recker (1979), Green and Krieger (1996), Guadagni and Little (1983), Hensher and Johnson (1980), Louviere (1988), Louviere and Timmermans (1990), and McFadden (1986). Thus, rather than repeat what already is well known and well worn, we only summarize the main ideas behind the approach in this article.

Naturally, DCA is not the only approach that has been used to understand and model consumer decision making, but it has proved to be particularly valuable in many hundreds of applications since its introduction by McFadden (1974). More important, DCA is one of the few modeling approaches that is 
based on a relatively comprehensive behavioral theory (i.e., random utility theory, discussed later) that leads to a wide variety of testable and tractable models of consumer choice behavior. At the same time, it is worth noting that all models are "abstractions of reality" and not necessarily reality itself. The applicability of a particular model depends on the assumptions, theoretical foundations, and scientific methods used in modeling, data collection, and analysis. Therefore, although the following subsections provide only a general overview of DCA, it should be noted that the approach can be adapted to fit many specific research situations and applications.

Information integration theory (IIT) in psychology (e.g., Anderson 1981, 1982) and random utility theory (RUT) in econometrics (e.g., Ben-Akiva and Lerman 1991; Hensher and Johnson 1980) provide the theoretical basis for our operationalization of DCA. In particular, research suggests that after acquiring information and learning about possible alternatives, decision makers define a set of determinant attributes to use to compare and evaluate alternatives. After comparing available alternatives with respect to each attribute, decision makers eliminate some alternatives and form a final choice set $(\mathrm{Cn})$ containing $n$ alternatives. They then form impressions of each alternative's position on the determinant attributes, value these attribute positions vis-à-vis one another (i.e., make trade-offs), and combine the attribute information to form overall impressions of each alternative. Figure 1 presents a simple model of this process.

Economic choice theory assumes that individuals' choice behavior is generated by maximization of preferences or utility. Louviere (1988) defines utility as "judgments, impressions, or evaluations that decision makers form of products or services, taking all the determinant attribute information into account" (p. 12). The idea of utility maximization and its relation to human choice behavior is not new. McFadden (1986) quotes from a 1912 economics text by Taussig:

An object can have no value unless it has utility. No one will give anything for an article unless it yields him satisfaction. Doubtless people are sometimes foolish and buy things, as children do, to please a moment's fancy; but at least they think at the moment that there is a wish to be gratified.

According to IIT, after forming the impressions of the positions of various physical attributes $\left(S_{a j}\right)$, decision makers make value judgments about the attractiveness (or partworth utility) of each attribute $\left(V\left[S_{a j}\right]\right)$. Next, they integrate the information about different determinant attributes to form the overall impression (utility: $U_{j}$ ) of each alternative. Hence, the probability of choosing a particular alternative $\left(P_{j} \mid C_{n}\right)$ is determined by its overall utility $\left(U_{j}\right)$, which in turn is a function of decision makers' subjective judgments $\left(V\left[S_{a j}\right]\right)$ of their perceptions $\left(S_{a j}\right)$ of the alternative's actual physical attributes $\left(X_{a j}\right)$. Mathematically, these ideas can be represented as

$$
\left(P_{j} \mid C_{n}\right)=f_{4}\left(f _ { 3 } \left\{f _ { 2 } \left[f_{1}\left(X_{a j}\right)=F\left(X_{a j}\right) \text { for } a \leftrightarrow A, j \leftrightarrow C_{n}\right.\right.\right.
$$

where $A$ is the set of determinant attributes; $f_{1}-f$ represents functions linking $X_{a j}, S_{a j} V\left(S_{a j}\right), U_{j}$, and $P_{j} ; F$ is a combination function of $f 1, f 2, f 3$, and $f 4 ;(P j \mid C n)$ is the probability of choosing alternative $j$ in choice set $n$; and $X_{a j}$ is alternative $j^{\prime}$ s true physical attribute $a$.

In words, Equation 1 represents the probability that an individual will choose an alternative as a function of the alternative's determinant attributes. Equation 1 also indicates that several different levels of explanation of choice behavior are possible: (a) explanations based on physical variables, (b) 
explanations based on belief variables, (c) explanations using part-worth utilities, and/or (d) explanations containing combinations of these variables (Louviere 1988). Most researchers in marketing research and other disciplines have chosen to explain consumer choice behavior in terms of determinant attributes of the alternatives (Ben-Akiva and Lerman 1991; Hensher and Johnson 1980; Louviere 1988). However, in general, firms seek to explain choice behavior in terms of physical variables that underlie attributes because managers can manipulate such variables.

In addition, in many applications of DCA, certain assumptions about the distributions of errors in the valuation process lead to the consequence that changing the number of alternatives in choice sets does not change the relative probabilities of choice among the alternatives. This property is known as independence from irrelevant alternatives (IIA) (Ben-Akiva and Lerman 1991; Louviere 1988) and is a consequence of assuming that the errors in the valuation process are IID Gumbel distributed random variates. Although potentially unrealistic, the IIA property can be valuable in applications because it allows one to predict to alternatives not currently in choice sets or to choice sets of various sizes. In turn, choice models that possess the IIA property can be estimated from certain types of choice experiments (Louviere and Woodworth 1983), which then permit researchers to predict the probability that alternatives with given attribute levels will be chosen by consumers. That is, the relative probability of choosing any alternative depends on the attributes of the alternatives. Hence, these probabilities can be modeled and predicted and used to estimate market shares of products or services.

It is now well known that the conditional probability of choosing an alternative from a given choice set can be expressed as a multinomial logit ( $\mathrm{MNL}$ ) model if the random components of utility (i.e., the errors in the valuation process) are IID Gumbel distributed random variates (Ben- Akiva and Lerman 1991; Gensch and Recker 1979; Guadagni and Little 1983; Louviere 1984; Louviere and Timmermans 1990; McFadden 1986). Other forms of choice models (e.g., nested logit models) can be derived by relaxing the IID error assumption, but for purposes of illustration and exposition, this article focuses on the MNL model. The MNL model is expressed as

$$
\left(P_{j} \mid C_{n}\right)=\frac{e^{V_{j} \mu}}{\sum_{k=1}^{n} V_{k} \mu}
$$

where $V_{j}$ represents the systematic component of utility $\left(U_{j}\right)$ of alternative $j$. MNL is a member of the family of random utility models, which assume that the utilities $\left(U_{j}\right)$ of real interest are latent, unobservable constructs. These latent utilities can be represented by a systematic (or explainable) component $\left(V_{j}\right)$, which can be estimated, and a random (or unexplainable) component $(\varepsilon)$, which, in the case of MNL, is independent and identically distributed according to a Gumbel distribution with a scale parameter $\mu$. We can decompose any product or service into a bundle of attributes, and if we assume that utility is additive in the part-utility of each attribute, then we can represent an alternative's systematic utility as follows:

$$
V_{j}=\sum_{a \in A} \beta_{a} X_{a j}
$$

where $\beta_{a}$ is the relative utility (part-worth utility) associated with attribute $a$. In practice, the $\beta_{a}$ parameters are estimated by means of the method of the maximum likelihood (Ben-Akiva and Lerman 1991). 
DCA often has been compared with another popular marketing research method known as conjoint analysis, which it resembles superficially in that it too is based on analyzing consumers' responses to experimentally designed profiles of products/services. However, DCA and conjoint analysis differ from each other in terms of their assumptions, statistical theory, and data analysis procedures.

Generally speaking, DCA and conjoint analysis have some superficial similarities, although conjoint analysis does not generally have an underlying theory of behavior but rather is a theory about data (with IIT possibly being an exception). In addition, RUT not only provides DCA with sound, welltested, and often applied behavioral theory, it also provides a framework with which to compare preference data from a very wide range of elicitation procedures and data sources and to model not only choices but also volumes and interpurchase times conditional on choices, delays, and nonpurchases as well as a variety of other aspects of real market behaviors (e.g., trial and repeat). More important, RUT provides a sound, theoretical link between behavior observed in experiments, surveys, or other forms of stated preferences and behavior observed in real markets (Louviere 1994; Louviere, Fox, and Moore 1993; Swait and Louviere 1993). By contrast, conjoint analysis is a static, one-profile-at-a-time elicitation procedure that lacks a strong behavioral foundation and provides no mechanism for modeling volumes and interpurchase times, delay, nonpurchase, or other customer behaviors of primary strategic interest. Moreover, conjoint analysis provides no theoretical link to behavior in real markets. Despite such significant differences, both procedures share some superficial similarities, which might underlie some of the confusion evident in the academic and practitioner literatures that has led some to believe that they somehow are the same.

Conjoint response data typically are obtained in the form of ratings (on a predetermined scale such as 1 to 100), rankings of experimental profiles (the respondents do not "choose" any alternative), or (more rarely) binary responses. In the case of ratings, analysts implicitly assume that the response data are "equal interval" in measurement level, which justifies use of ordinary least squares regression to estimate preference models. Models are estimated at an individual respondent level, and predictions of expected profile choices typically are made with no allowance for model errors. By contrast, DCA response data are categorical $(0,1)$ and require forms of discrete multivariate models to be used to analyze data (e.g., MNL, more complex models). Consequently, DCA typically is applied to analyze choice data supplied by aggregates of respondents, such as segments, which requires much more sophistication in design and analysis to account for different choice processes (e.g., non-IID error processes) and market characteristics such as heterogeneity in preference parameters (see, e.g., Louviere, Hensher, and Swait forthcoming).

To summarize, then, experimental design, data collection, and initial data analysis for individual respondents are easier for conjoint analysis, whereas it is relatively complicated to use conjoint analysis for predicting aggregate market share. By contrast, experimental design and data analysis are relatively more complex for DCA, but DCA has a high predictive accuracy for aggregate data sets. Therefore, we believe that DCA is the more valuable research tool for service management researchers. Table 1 summarizes the similarities and differences between DCA and conjoint analysis.

\section{Designing and Conducting Discrete Choice Studies}

As mentioned earlier, building on the IIT and economic choice theory, DCA identifies trade-off (or choice) coefficients for different attributes based on the decision makers' responses to experimentally designed profiles of possible alternatives. Empirical data collected from a random 
sample of respondents are used to estimate the relative importance of the alternatives' different attributes using MNL or more complex models of the consumers' choice process. Typically, DCA requires analysts to design both profiles (e.g., quick-service establishments with different attributes such as food quality, cost, and delivery time) and choice sets into which to place them to satisfy both identification and precision requirements of the parameters of particular utility specification and choice process models. DCA also can be used to analyze stated preferences obtained in surveys of various types as well as choices observed in real markets. As mentioned earlier, RUT allows all forms of preference data to be analyzed and allows preference parameters to be compared, including the important activity of relating real market choices and stated preferences (Ben-Akiva and Morikawa 1991; Louviere, Hensher, and Swait forthcoming).

\begin{tabular}{|c|c|c|}
\hline Criterion & Conjoint Analysis & Discrete Choice Analysis \\
\hline Type of data & Experimental & $\begin{array}{l}\text { Experimental/nonexperimental survey, revealed } \\
\text { market data }\end{array}$ \\
\hline Independent variables & Attributes of the alternatives & $\begin{array}{l}\text { Attributes of the alternatives and characteristics of } \\
\text { decision units }\end{array}$ \\
\hline $\begin{array}{l}\text { Dependent variable (respondent's } \\
\text { task) }\end{array}$ & Rating or ranking of alternatives & $\begin{array}{l}\text { Discrete choice of one alternative from choice sets } \\
\text { of two or more alternatives }\end{array}$ \\
\hline Experimental instrument & Descriptions of alternatives & Choice sets \\
\hline Presentation of alternatives & One alternative at a time & Several alternatives at a time \\
\hline Experimental design(s) & $\begin{array}{l}\text { Full or more typically fractional factorial } \\
\text { designs that generate alternatives } \\
\text { (profiles) }\end{array}$ & $\begin{array}{l}\text { Fractional factorial designs used to generate both al- } \\
\text { ternatives and the choice sets in which they } \\
\text { compete }\end{array}$ \\
\hline Types of behavioral processes & $\begin{array}{l}\text { Static preference formation and valua- } \\
\text { tion }\end{array}$ & $\begin{array}{l}\text { Preference conditional on a choice process and } \\
\text { competing alternatives }\end{array}$ \\
\hline Experimental design sophistication & $\begin{array}{l}\text { Relatively standard design theory for lin- } \\
\text { ear models }\end{array}$ & $\begin{array}{l}\text { Sophisticated and emerging designs for nonlinear } \\
\text { models and simultaneously competing alternatives }\end{array}$ \\
\hline Estimation method(s) & $\begin{array}{l}\text { Typically ordinary least squares regres- } \\
\text { sion, more rarely ordered and cen- } \\
\text { sored dependent variable models }\end{array}$ & $\begin{array}{l}\text { Families of logit, probit, and GEV models for discrete } \\
\text { dependent variables, and joint discrete/continu- } \\
\text { ous or discrete/ordered and/or conditional } \\
\text { nested models }\end{array}$ \\
\hline $\begin{array}{l}\text { Level of sophistication required for } \\
\text { data analysis }\end{array}$ & Relatively little sophistication & Very considerable sophistication \\
\hline Analytical outputs & $\begin{array}{l}\text { Utility functions and naive choice pre- } \\
\text { dictions based on maximum utility } \\
\text { rule }\end{array}$ & $\begin{array}{l}\text { Utility functions conditions on choice process lead- } \\
\text { ing directly to choice predictions, but also vol- } \\
\text { umes conditional on choices and other more } \\
\text { sophisticated and complex behaviorally inter- } \\
\text { linked outputs }\end{array}$ \\
\hline Levels of analysis & $\begin{array}{l}\text { Individual level and aggregates of indi- } \\
\text { viduals }\end{array}$ & $\begin{array}{l}\text { Almost always aggregates of individuals, but } \\
\text { individual-level analysis possible in some cir- } \\
\text { cumstances }\end{array}$ \\
\hline Market validation mechanism & $\begin{array}{l}\text { None based on theory, but calibration } \\
\text { may be possible }\end{array}$ & $\begin{array}{l}\text { Combining market and stated preference data based } \\
\text { on random utility theory }\end{array}$ \\
\hline
\end{tabular}

SOURCE: Adapted from Louviere $(1988,1994)$ and Louviere and Timmermans (1990).

Table 1 Conjoint and Discrete Choice Analysis: Similarities and Differences

For the purposes of this article, we confine the discussion to DCA applications involving discrete choice, stated preference experiments. Such experiments involve the design of profiles and choice sets in which two or more alternatives are offered to decision makers, who are asked to evaluate the options and to choose one (or none). In more complex DCA experiments, decision makers are asked to indicate usage (volumes) conditional on choice and/or interpurchase times and the like. Typically, each respondent in a DCA experiment receives several choice sets to evaluate (e.g., 8 to 32 sets). The design of the experiment is under the control of the researcher, and consequently, the decision makers' choices (dependent variable) must be a function of the attributes of each alternative, personal characteristics of the respondents, and unobserved effects captured by the random component (e.g., 
unobserved heterogeneity, omitted factors). Since its introduction by Louviere and Woodworth (1983), DCA has seen hundreds (if not thousands) of applications in marketing, transportation, operations management, product design and development, and recreation and leisure research (Ben-Akiva and Lerman 1991; Ben-Akiva and Morikawa 1991; Louviere 1984; Louviere, Swait, and Williams 1994; Louviere and Timmermans 1990; Swait and Louviere 1993).

Like most other social and behavioral science fields, service management researchers also are interested in human (i.e., customers, managers) choice behavior. For example, it is important for restaurants, health care providers, banks, insurance brokers, and car repair establishments to understand the relative importance of various service attributes from a customer's point of view. Indeed, they should be interested in knowing the impact of a given service configuration on customer choice and demand as well as management's ability to meet the specified customer needs. Therefore, DCA should be able to provide valuable strategic and predictive insights that can contribute to more effective service management.

DCA applications based on choice experiments typically involve the following steps: identification of attributes, specification of attribute levels, experimental design, presentation of alternatives to respondents, and estimation of choice model. In the subsections that follow, we illustrate the preceding DCA steps using an actual DCA application in the pizza delivery Industry. The pizza delivery industry is particularly interesting because customers' preferences and choices are expected to be influenced by several operating variables (e.g., waiting time, service reliability, food temperature) in addition to cost and other product attributes (e.g., types of pizza crust).

\section{Identification of Attributes}

The first step in implementing a discrete choice experiment is to identify the determinant attributes used in decision makers' evaluation process. Great care must be taken to ensure that all (or at least as many as possible) of the determinant decision attributes are identified and expressed in terms understood by the consumers to be studied. Qualitative market surveys, interviews, case studies, and/or focus groups typically are used to identify a set of such relevant attributes, but reviews of practitioner and academic literatures relevant to the study also might be necessary. For example, Louviere and Timmermans (1990) suggest that one consider the following when building a list of attributes. First, is it necessary to include an exhaustive list of all salient attributes? Second, which attributes can be retained, recombined, or reexpressed to keep the set of attributes as nonredundant and as small as possible to make the experiment tractable but realistic?

To identify the relevant attributes for the pizza delivery industry, we collected qualitative data from 15 randomly selected customers and three pizza delivery establishment managers. There were several reasons for collecting this form of data prior to experimental design. The operations strategy literature suggests that a service firm's market-based objectives can be classified into the following broad categories: product quality, service quality, delivery, flexibility, and cost; product quality can be further divided into 8 dimensions, and service quality can be further divided into 10 dimensions (Garvin 1987; Parasuraman, Zeithaml, and Berry 1985). Even if one variable is used for every market-based objective, the total number of variables in a choice experiment would be more than 20 , which would substantially increase the dimensionality of the design. Indeed, as the number of variables increases, more experimental profiles and choice sets are needed to accurately estimate all the model parameters. In addition, certain pizza attributes (e.g., types of cheese, standard toppings) might be offered at the 
same level or nearly similar levels in all the alternatives and so might not be determinants in choice of pizza delivery company.

To keep the study relatively less complex, we selected seven attributes to describe pizza delivery services: promised delivery time, actual delivery time, pizza variety, pizza temperature, unconditional money-back guarantee, price, and discount on a second pizza. We decided to ignore "gourmet" pizza attributes because only a limited number of establishments in our study area deliver such pizzas. We note, however, that choice experiments can be designed for larger numbers of attributes and alternatives than this illustration, although this typically leads to larger and more complicated designs or modifications in data collection and/or analysis procedures. For example, Louviere et al. (1995) review a variety of ways in which to deal with the large number of attributes in discrete choice studies.

\section{Specification and Attributes Levels}

Attribute ranges often are chosen to span the actual values observed in the marketplace and/or to represent values expected to occur during the planning horizon. At the same time, the range of an attribute should not be so large that the choice experiment becomes unrealistic or the respondents have difficulty visualizing or imagining that it could occur. Once the range is determined, it must be divided into two or more discrete levels for design purposes. Two levels are sufficient to estimate the linear effect of the attributes on choice, but more than two levels are needed to estimate nonlinear effects for quantitative attributes, although more levels might lead to larger designs. Indeed, Hagerty (1986) demonstrates that complex models predict aggregate market shares of actual products/services more accurately than do simple models, and Louviere et al. (1995) discuss the fact that several fields outside of marketing routinely design and apply large and complex experiments to elicit preferences. Thus, service management researchers should consider how differences in the numbers of attributes and levels will affect realism, design efficiency, and model specification possibilities.

Because our study is more illustrative than definitive, we selected two attribute levels for each of the seven pizza delivery attributes described earlier. The two levels generally reflect the upper and lower extremes for each attribute for most pizza delivery establishments in our study area. Table 2 contains the attributes and corresponding levels.

\begin{tabular}{lll}
\hline Attribute & Design Code $=-1$ & Design Code $=+1$ \\
\hline Price of first large pizza & $\$ 12$ & \$18 \\
Discount on second pizza & None & Half price \\
Promised delivery time & 20 minutes & 40 minutes \\
Actual delivery time & Same as promised & 15 minutes late \\
Pizza variety & One type of crust & Three types of crust \\
Pizza temperature & Warm & Steaming hot \\
Unconditional money-back guarantee & No & Yes \\
\hline
\end{tabular}

Table 2 Pizza Delivery Attributes and Levels

\section{Experimental Design}

Discrete choice experiments can be designed in many ways, but we limit ourselves to the method proposed by Louviere and Woodworth (1983) that involves treating all the attributes of choice alternatives as factors in a combined factorial design and selecting the smallest orthogonal fraction that spans the space formed by all attributes. By making the design in this way, all attributes are simultaneously varied independently to create both alternatives and choice sets. In practice, fractional 
factorial designs are used to make these designs because most choice experiments quickly become very large with even modest numbers of attributes and alternatives (Hahn and Shapiro 1966; Louviere 1988; McLean and Anderson 1984). To our knowledge, at the present time, there is no agreement on how to generate optimally efficient choice sets, although research in this area has made some advances in this direction (Anderson and Wiley 1992; Huber and Zweringa 1991).

In the case of the present pizza delivery application, we first generated a 16-profile orthogonal fractional design that allows estimation of all main effects and selected two way interactions. Because all attributes were at two levels, took advantage of a unique property of two-level attribute= designs to combine the 16 profiles with their corresponding "foldover" profiles to create pairs of competing pizza delivery service profiles. The foldover of a profile is simply its mirror image. For example, a profile with a pizza price of $\$ 18$ and a $50 \%$ discount on a second pizza has a foldover of pizza price of $\$ 12$ and no discount on a and pizza ( $\$ 12$ vs. $\$ 18$ and $50 \%$ discount vs. no discount are two levels in the pizza study). Design codes for each of the 16 profiles are presented in Table 3.

\begin{tabular}{|c|c|c|c|c|c|c|c|c|c|c|c|c|c|c|c|c|}
\hline \multirow[b]{2}{*}{ Attribute } & \multicolumn{16}{|c|}{ Profile } \\
\hline & 1 & 2 & 3 & 4 & 5 & 6 & 7 & 8 & 9 & 10 & 11 & 12 & 13 & 14 & 15 & 16 \\
\hline Price of first large pizza & -1 & -1 & -1 & -1 & -1 & -1 & -1 & -1 & 1 & 1 & 1 & 1 & 1 & 1 & 1 & 1 \\
\hline Discount on second pizza & -1 & -1 & -1 & -1 & 1 & 1 & 1 & 1 & -1 & -1 & -1 & -1 & 1 & 1 & 1 & 1 \\
\hline Promised delivery time & -1 & -1 & 1 & 1 & -1 & -1 & 1 & 1 & -1 & -1 & 1 & 1 & -1 & -1 & 1 & 1 \\
\hline Actual delivery time & -1 & 1 & -1 & 1 & -1 & 1 & -1 & 1 & -1 & 1 & -1 & 1 & -1 & 1 & -1 & 1 \\
\hline Pizza variety & -1 & 1 & 1 & -1 & -1 & 1 & 1 & -1 & 1 & -1 & -1 & 1 & 1 & -1 & -1 & 1 \\
\hline Pizza temperature & -1 & 1 & 1 & -1 & 1 & -1 & -1 & 1 & -1 & 1 & 1 & -1 & 1 & -1 & -1 & 1 \\
\hline $\begin{array}{l}\text { Unconditional money-back } \\
\text { guarantee }\end{array}$ & -1 & -1 & 1 & 1 & 1 & 1 & -1 & -1 & 1 & 1 & -1 & -1 & -1 & -1 & 1 & 1 \\
\hline
\end{tabular}

Table 3 Experimental Design Mix

\section{Presentation of Alternatives and Choice Task}

A wide range of media can be used to describe hypothetical choice alternatives generated by the experimental design. For example, one can use sentences, short phrases, or paragraphs; pictures, drawings, photographs, or compute images; models; or any combination of written, visual or other sensory representation.

The final aspect of designing discrete choice experiments involves a decision about the type of task. Most DCA tasks offer two or more alternatives at a time to decision makers and ask them to choose one or none of them (Louviere and Timmermans 1990). But other response modes and task formats are possible. For example, one can use a traditional conjoint analysis protocol and show decision makers one experimental profile at a time and elicit a yes/no choice response. Other possibilities include asking for a single choice and then, conditional on that choice, selecting from a set of possible usage rates or interpurchase times.

Our experimental task was a relatively typical choice experiment in which respondents were offered three alternatives in each choice set (an original profile, the foldover of that profile, and a choice of neither) and were instructed to choose one. Each respondent completed all 16 choice sets in the design. Table 4 contains a sample choice set. 


\section{Data Collection and Choice Models Estimation}

Once the design is implemented in the form of a set of choice sets and accompanying discrete choice task, response data are collected from respondents representative of the population of interest. There remains no general agreement on a maximum number of choice sets per respondent, although recent research indicates that the number of sets for the type of task illustrated in this article is likely to be well over 20 (Brazell and Louviere 1998). Recent research also suggests that the primary concern is reliability of the choice data and not validity even for large numbers of sets (e.g., 50 or more) (Brazell and Louviere 1998). However, it is likely to be the case that as task complexity increases by increasing either the number of alternatives or the number of attributes or both, it would be prudent to reduce the number of sets administered to respondents. Pilot work can inform this decision, but ultimately it represents a trade-off between increasing the amount and quality of statistical information by increasing the size of the design, and hence the number of choice sets, versus decreasing the reliability of the choice data.

Responses to a discrete choice experiment are categorical because respondents choose only one alternative. Hence, the dependent variable typically is coded 1 for the chosen alternative and 0 for all unchosen alternatives in every choice set. Because discrete choice data contain less information about preferences than do some other forms of preference elicitation data, one typically cannot estimate discrete choice models for single individuals. In particular, there are too few observations/individuals to satisfy the asymptotic conditions for the model parameters and statistical tests that obtain only in large samples. Hence, responses from multiple respondents are used in model estimation.

As soon as one becomes involved in estimating models over aggregates of individuals, preference heterogeneity becomes an issue. Specifically, in nonexperimental applications of probabilistic discrete choice models, there are serious and real concerns about preference heterogeneity because an individual typically represents a choice set, and hence the attributes of alternatives vary from individual to individual (Ben-Akiva and Lerman 1991). Thus, in nonexperimental settings, heterogeneity is a structural issue. However, in the case of choice experiments, respondents typically and randomly are assigned to blocks of the experiments, and the purpose of the randomization is to orthogonalize the random effects to the model structure. Hence, in a typical choice experiment, heterogeneity is more of an efficiency issue because the parameter estimates are consistent and unbiased (all else equal). Thus, in this illustration, we ignore heterogeneity because all respondents participated in all choice sets, and our model parameters represent sample means that are unbiased and consistent.

The pizza delivery study was conducted in a large city in the western United States. In addition to the choice experiments, the survey instrument contained demographic questions (e.g., age, gender, education, household income) and information about companies from whom respondents had ordered pizza during the previous 6 months. Survey instruments were mailed to 500 residential addresses randomly selected from the city telephone directory. Each survey mailing also included a cover letter from the lead researcher and the chairperson of the Department of Management of a large state university along with a self-addressed, postage-paid business reply envelope. A total of 56 surveys were returned either because of incomplete addresses or because the residents had moved to new locations with no forwarding addresses, and 16 other surveys were returned unanswered because the recipients 
did not eat pizza or did not want to participate. A total of 145 total surveys were received by the cutoff date, but 17 of these were less than $25 \%$ complete and had to be discarded. Therefore, the effective response rate was $31.1 \%$.

Once the choice data were coded and edited, they were arranged into a data file and merged with the design matrix that represents the choice experiment. MNL models were estimated from the choice data using the NTELOGIT software package for logistic regression analysis (Intelligent Marketing Systems 1992). NTELOGIT uses the method of maximum likelihood to estimate the parameters of MNL models, their standard errors, and their asymptotic $t$ statistics. All models were reanalyzed using the NLOGIT module in LIMDEP (Econometric Software 1996) to ensure cross-validity.

\begin{tabular}{|c|c|c|c|c|c|}
\hline Attribute & $\begin{array}{c}\text { All } \\
\text { Respondents }\end{array}$ & $\begin{array}{c}\text { Ambassador } \\
\text { Pizza }\end{array}$ & $\begin{array}{l}\text { Domino's } \\
\text { Pizza }\end{array}$ & $\begin{array}{c}\text { Godfather's } \\
\text { Pizza }\end{array}$ & Pizza Hut \\
\hline Number of respondents & 128 & 31 & 56 & 30 & 76 \\
\hline Price of a large pizza & $-.614 *$ & $-.760 *$ & $-.318 *$ & $-.367 *$ & $-.520 *$ \\
\hline Half price for second pizza & $.222 *$ & $.212^{*}$ & .009 & $.200^{*}$ & $.248^{*}$ \\
\hline Promised delivery time & $-.179 *$ & $-.133^{*}$ & .032 & $-.255^{*}$ & $-.202^{*}$ \\
\hline Actual delivery time & $-.125^{*}$ & $-.163 *$ & .040 & -.082 & $-.136 *$ \\
\hline Pizza variety & $.273 *$ & $.525^{*}$ & $.131^{*}$ & $.341^{*}$ & $.305 *$ \\
\hline Pizza temperature & $.341^{*}$ & .129 & $.198 *$ & $.258^{*}$ & $.400^{*}$ \\
\hline Unconditional money-back guarantee & $.236^{*}$ & $.330^{*}$ & $.356^{*}$ & $.210^{*}$ & $.240^{*}$ \\
\hline Intercept & $.726^{*}$ & $.745^{*}$ & $.922 *$ & $.969 *$ & $.721^{*}$ \\
\hline$\rho^{2}$ & .871 & .752 & .550 & .671 & .815 \\
\hline Adjusted $\rho^{2}$ & .858 & .717 & .524 & .625 & .794 \\
\hline
\end{tabular}

NOTE: Boldface figures indicate most important attributes. Boldface italic figures indicate second most important attributes ${ }^{*} p<.05$

Table 5 Estimated Multinomial Logit Models

Table 5 contains several MNL models-one for the entire sample and the others for customers who ordered pizza from one of the four major chains in the area during the past 6 months. The estimated coefficients in Table 5 represent the relative weights or part-worth utilities associated with each of the pizza delivery service attributes.

Table 5 shows that several attributes were statistically significant for the whole sample. The signs of the estimated coefficients for promised delivery time, actual delivery time, and price are negative, which means that the probability of selecting a pizza delivery company decreases with increases in these attributes. The signs of all the other attributes are positive, which means that the probability of selecting a company increases if it offers more variety, steaming hot pizza, a money-back guarantee, or a second pizza discount. In summary, the experimental results reveal that customers choose pizza delivery companies based on product quality (variety, pizza temperature), service quality (promised and actual delivery times, money-back guarantee), delivery (promised and actual delivery times), flexibility (variety), and cost (price)-based attributes.

Several goodness-of-fit statistics (e.g., log likelihood ratio, Akaike information criteria) can be calculated for each MNL model. For example, Table 5 contains McFadden's $\rho^{2}$ and adjusted $\rho^{2}(.858)$ for each MNL model, which is similar to $R^{2}$ and adjusted $R^{2}$ in ordinary least squares regression. $\rho^{2}$ varies between 0 and 1 and measures the degree of fit with respect to the estimated parameters.

In Table 5, the two largest attribute parameters for each model are highlighted, although we caution that numerical parameter values for different MNL models cannot be compared directly 
because the Gumbel scale parameter ( $m$ in Equation 2) differs for each model. $\mu$ cannot be identified separately in any one model; consequently, if one ishes to compare two MNL models statistically, then chi-square test based on the null hypothesis that the only difference in the model parameters is the ratio of the two model error variances is required. As discussed by Swait and Louviere (1993), this rescaling of one model relative to a reference represents a parameter restriction that the parameters of one model be proportional to the parameters of the reference model.

The experimental design for the customer choice experiment allows us to estimate the two-way interactions among the following attributes: promised delivery time, actual delivery time, pizza variety, and price. This new utility specification requires a subsequent estimation, but none of the interactions was found to be statistically significant at the $5 \%$ level, and hence only the MNL models without interactions are presented and discussed further (Table 5).

\section{Managerial Use of Multinomial Models}

The information collected in the form of MNL choice models can be used to predict the expected market shares of each competitor within a given market. That is, the MNL model represented by Equation 2 gives the probability of selecting one alternative from a set of alternatives. The numerator gives the utility of a particular alternative, and the denominator is a sum of utilities for all competitors. In other words, the coefficients for each attribute (the b vector in Equation 2, the estimated b's in Table 5) allow one to calculate the utility of each competitor and, hence, also their expected market shares. A simple example presented in the following paragraphs illustrates the use of the MNL model as a decision support system (DSS).

Assume that there are only three pizza delivery establishments-Comp1, Comp2, and Comp3-in the geographic area from which discrete choice data were collected. The assumed pizza attribute levels for the three companies are in Table 6 . Comp1 charges $\$ 12$ for a delivered pizza and gives a $50 \%$ discount on a second pizza; it offers only one type of pizza crust, promises to deliver pizza in 40 minutes but is 10

\begin{tabular}{|c|c|c|c|c|c|c|c|c|c|}
\hline \multirow[b]{2}{*}{ Attribute } & \multicolumn{3}{|c|}{ Compl } & \multicolumn{3}{|c|}{ Comp2 } & \multicolumn{3}{|c|}{ Comp3 } \\
\hline & $\begin{array}{c}\text { Attribute } \\
\text { Value }\end{array}$ & $\begin{array}{c}\text { Design } \\
\text { Code }(X I)\end{array}$ & $X I * \beta$ & $\begin{array}{c}\text { Attribute } \\
\text { Value }\end{array}$ & $\begin{array}{c}\text { Design } \\
\text { Code }(X 2)\end{array}$ & $X 2 * \beta$ & $\begin{array}{c}\text { Attribute } \\
\text { Value }\end{array}$ & $\begin{array}{c}\text { Design } \\
\text { Code }(X 3)\end{array}$ & $X 3^{*} \beta$ \\
\hline Price of first large pizza & $\$ 12$ & -1 & .614 & $\$ 15$ & 0 & .000 & $\$ 18$ & 1 & -.614 \\
\hline Discount on second pizza & Yes & 1 & .222 & Yes & 1 & -.222 & No & -1 & -.222 \\
\hline Promised delivery time & 40 minutes & 1 & -.179 & 30 minutes & 0 & -.179 & 20 minutes & -1 & .179 \\
\hline Actual delivery time & 50 minutes & .33 & -.042 & 35 minutes & -.33 & .125 & 20 minutes & -1 & .125 \\
\hline Pizza variety & 1 & -1 & -.273 & 2 & 0 & .273 & 3 & 1 & .273 \\
\hline Pizza temperature & Warm & -1 & -.341 & Warm & -1 & .341 & Hot & 1 & .341 \\
\hline $\begin{array}{l}\text { Unconditional money-back } \\
\text { guarantee }\end{array}$ & No & -1 & -.236 & Yes & 1 & .236 & Yes & 1 & .236 \\
\hline Utility $(V=\Sigma \times \beta)$ & & & -.2347 & & & .1587 & & & .318 \\
\hline$e^{\mathrm{v}}$ & & & .7908 & & & 1.1719 & & & 1.3744 \\
\hline Market share $\left(e^{\mathrm{V}} / \Sigma e^{\mathrm{V}}\right)$ & & & $23.70 \%$ & & & $35.12 \%$ & & & $41.18 \%$ \\
\hline
\end{tabular}

Table 6 A Managerial Example

minutes late on average, and does not offer money-back guarantees. Comp2 is relatively expensive ( $\$ 18$ per pizza) but delivers pizza in 20 minutes and offers three types of crusts. Comp3 prices are between those of Comp1 and Comp2, and the company promises to deliver pizza in 30 minutes but is 5 minutes 
late on average. Table 6 contains attributes and corresponding design codes for the three pizza delivery companies.

The design codes for the attributes can be multiplied by their respective MNL attribute coefficients (from Table 5) and summed to calculate overall company utility. Expected market shares for the three companies then are calculated using the MNL model as shown in Table 6. This approach yields expected market shares for Comp1, Comp2, and Comp3 of 23.70\%, 35.12\% and 41.18\%, respectively. The MNL model also can be used to evaluate the expected changes in market share if one or more attribute levels are changed by one or more companies. For example, let Comp1 offer two types of pizza crust. This is easily incorporated into the MNL model by changing the code for pizza variety from -1 to 0 and recalculating the market shares $(28.98 \%, 32.69 \%$, and $38.33 \%$ for Comp1, Comp2, and Comp3, respectively). Thus, Comp1 will gain $5.28 \%$ market share at the expense of $2.43 \%$ and $2.85 \%$ market share losses for Comp2 and Comp3, respectively.

A number of past studies have shown that, in general, the market share predictions generated from MNL models based on DCA are relatively accurate (Ben-Akiva and Lerman 1991; Green and Krieger 1996; Louviere and Timmermans 1990). Of course, the accuracy of market share predictions for a specific study will depend on the robustness of the experimental design, levels, and attributes; the appropriateness of the sample selection; and the changes in the market conditions from data collection to prediction.

\section{Discussion}

Understanding the choice behavior of customers or managers is important for effective service management because it provides insights into decision-making processes of individuals. By understanding consumer choice modeling, managers can position service offerings to better suit market needs. Mathematical models representing consumer choice can be linked to several operating decisions (e.g., labor scheduling, special activities planning, service offerings), and optimal service configurations can be identified for further improvement. The empirical application in this article demonstrates that DCA can help both academics and managers achieve these goals effectively. The following paragraphs discuss various possible implications of DCA in service businesses.

The MNL model developed from the discrete choice data can be incorporated into spreadsheet programs as a DSS. Although design of choice experiments and estimation of MNL models requires sophisticated training and skills, implementing the estimated models in spreadsheet-based DSSs is fairly easy. Table 6 shows a simple example of a DSS in which one can program the spreadsheet to predict the probability of selecting an offering based on the estimated $b$ coefficients. Once the DSS is available, a manager needs only to input the attributes of his or her own products and those of competitors' products to predict expected market shares. The DSS also can be used to estimate the impact of changing levels of one or more attributes by any one company and/or competitors. In fact, the dynamic nature of the market is essentially approximated by the DSS, which allows managers to evaluate multiple business, operating, and/or marketing strategies.

The predictive power of DCA-based MNL models can be further improved by market segmentation techniques. For example, Moore, Gray-Lee, and Louviere (1998) recently showed that a latent segment procedure based on DCA outperforms several other market segmentation techniques. 
Moore, Gray-Lee, and Louviere's procedure assigns consumers to different market segments based on their actual choice behaviors and, consequently, predicts actual marketplace choices well.

MNL models and associated DSS's also can be used as education and training tools to help managers better understand customer needs and better match their offerings to what customers want and are willing to pay for. Managers of large service organizations (e.g., hotels, resorts) often are far removed from the customers and/or are too busy managing day-to-day operations, and hence a gap may exist between managers' perceptions of customer needs and customers' actual needs. Such a "perception-choice" gap can be identified by comparing two MNL models: one representing customer choices and a second representing managers' beliefs about customer choices. The statistical test developed by Swait and Louviere (1993) allows one to compare the two MNL models and determine the significant differences.

Customer choice information obtained from DCA can be used to design services and/or to effectively manage process operations. For example, assume that customers of a particular quick-service restaurant place more weight on waiting time relative to the number of food items on the menu. In that case, managers should focus their attention of scheduling labor force and/or streamlining operations to reduce waiting time if the costs of so doing prove to be profitable compared to the same analysis for decreasing food items to speed up the order preparation cycle. MNL models can predict the impact of each of these strategies. For example, a recent application involved an analysis of customer choice and waiting time in the ski industry using choice data and a sophisticated computer simulation model to evaluate the best choices for capacity expansion and target markets for a particular ski resort (Pullman and Moore forthcoming). Another recent study examined the use of MNL choice models in scheduling frontline customer service representatives (Goodale, Pullman, and Verma 1998).

DCA often is compared with conjoint analysis, which also involves an analysis of consumer responses to experimentally designed product/service profiles. As noted earlier in this article, DCA and conjoint analysis resemble one another only superficially and differ significantly in assumptions, behavioral and statistical theory, and modeling procedures. Only DCA is based on a comprehensive behavioral theory that allows one to combine sources of preference data as well as rescale models from surveys, experiments, and other sources of stated preference data to match choices in real markets.

This study has presented an overview of DCA and has illustrated how it can be used to effectively integrate customer preferences and choices into operating decisions in service businesses. We described and discussed the theory and associated analytical methods, reviewed a number of other applications, and demonstrated the usefulness of DCA as a decision support tool in service management research. These and other results cited in this article serve to demonstrate that DCA can improve the financial and market positions of firms operating in competitive service industries. Further references can be found in Table 7, which contains brief descriptions of various publications related to DCA.

\section{References}

Anderson, D. A. and J. B. Wiley (1992), "Efficient Choice Set Designs for Estimating Availability CrossEffects Models," Marketing Letters, 3 (4), 357-70.

Anderson, E.W., C. Fornell, and R. Rust (1997), "Customer Satisfaction, Productivity, and Profitability: Differences between Goods and Services," Marketing Science, 16 (2), 129-45. 
Anderson, N. H. (1981), Foundations of Information Integration Theory. New York: Academic Press. -(1982), Methods of Information Integration Theory. New York: Academic Press.

Ben-Akiva, M. and S. R. Lerman (1991), Discrete Choice Analysis. Cambridge, MA: MIT Press. -and T. Morikawa (1991), "Estimation of Travel Demand Models from Multiple Data Sources," in Transportation and Traffic Theory, M. Koshi, ed. Amsterdam: Elsevier.

Bowen, D. E. and T. G. Cummings (1990), "Suppose We Took Service Seriously," in Service Management Effectiveness. San Francisco: Jossey-Bass.

Brazell, J. D. and J. J. Louviere (1998), "Length Effects in Conjoint Choice Experiments and Surveys: An Explanation Based on Cumulative Cognitive Burden," working paper, University of Sydney.

Carmone, F. J. and P. E. Green (1987), "Model Misspecification in Multiattribute Parameter Estimation," Journal of Marketing Research, 18 (2), 87-93.

Chase, R. B. (1996), "The Mall Is My Factory: Reflections of a Service Junkie," Production and Operations Management, 5 (4), 298-308.

Currim, I. S. (1981), "Using Segmentation Approaches for Better Prediction and Understanding from Consumer Mode Choice Models. Journal of Marketing Research, 18 (August), 301-9.

Davidow, W. H. and B. Uttal (1989), "Service Companies: Focus or Falter," Harvard Business Review, 67 (July-August), 77-85.

DeSarbo, W. S., M. Wedel, M. Vriens, and V. Ramaswamy (1992), "Latent Class Metric Conjoint Analysis," Marketing Letters, 3 (July), 273-89.

Dillon, W. R., A. Kumar, and M. Smith de Borrero (1993), "Capturing Individual Differences in Paired Comparisons: An Extended BTL Model Incorporating Descriptor Variables," Journal of Marketing Research, 30 (February), 42-51.

Econometric Software (1996), LIMDEP: Program and User Guide. New York: Econometric Software.

Elrod,T., J. J. Louviere, and K. S. Davey (1992), “An Empirical Comparison of Rating-Based and ChoiceBased Conjoint Models," Journal of Marketing Research, 29 (August), 368-77.

Finn, A. and J. J. Louviere (1992), "Determining the Appropriate Response to Evidence of Public Concern: The Case of Food Safety," Journal of Public Policy and Marketing, 11 (1), 12-25.

Garvin, D. A. (1987), "Competing on the Eight Dimensions of Quality," Harvard Business Review, 65 (November-December), 101-9.

Gensch, D. H. (1985), "Empirically Testing a Disaggregate Choice Model for Segments," Journal of Marketing Research, 22 (November), 462-67.

Gensch, D. H. andW.W. Recker (1979), "The Multinomial, Multiattribute Logit Choice Model," Journal of Marketing Research, 16 (2), 124-32. 
Goodale, J. C., M. E. Pullman, and R. Verma (1998), "A Market Utility-Based Framework for Scheduling Customer Service Representatives," paper presented at the annual meeting of the Production and Operations Management Society, Santa Fe, NM, March.

Green, P. E. and A. M. Krieger (1991), "Segmenting Markets with Conjoint Analysis," Journal of Marketing, 55 (October), 20-31. -and----------- (1996), “Individualized Hybrid Models for Conjoint Analysis," Management Science, $42(6), 850-67$. -and V. Srinivasan (1990), "Conjoint Analysis in Marketing: New Developments with Implications for Research and Practice," Journal of Marketing, 54 (October), 3-19.

Griffin, A. and J. R. Hauser (1993), "The Voice of the Customer," Marketing Science, 12 (1), 1-27.

Guadagni, P. M. and J. D. Little (1983), "A Logit Model of Brand Choice Calibrated on Scanner Data," Marketing Science, 2 (3), 203-37.

Hagerty, M. R. (1986), “The Cost of Simplifying Preference Models," Marketing Sciences, 5 (4), 298-319.

Hahn, G. J. and S. S. Shapiro (1966), A Catalog and Computer Program for the Design and Analysis of Orthogonal Symmetric and Asymmetric Fractional Factorial Experiments. New York: General Electric Research and Development Center.

Hensher, D. A. and L. Johnson. (1980), Applied Discrete Choice Modelling. London: Croom Helm.

Heskett, J. L. (1987), "Lessons in the Service Sector," Harvard Business Review, 65 (March-April), 118-26.

Horowitz J. L. and J. J. Louviere (1993), "Testing Predicted Choices against Observations in Probabilistic Discrete-Choice Models. Marketing Science, 12 (3), 270-79.

Huber, J. and K. Zweringa (1991), "The Importance of Utility Balance in Efficient Choice Set Designs, Journal of Marketing Research, 33 (August), 307-17.

Intelligent Marketing Systems (1992), NTELOGIT: Software and User's Manual. Edmonton, Alberta: Intelligent Marketing Systems.

Karmarkar, U. S. (1996), "Integrative Research in Marketing and Operations Management," Journal of Marketing Research, 33 (May), 125-33. - and R. Pitbladdo (1995), "Service Markets and Competition," Journal of Operations Management, 12, 397-411.

Kordupleski, R. E., R. T. Rust, and A. J. Zahorik (1993), “Why Improving Quality Doesn't Improve Quality (or Whatever Happened to Marketing?)," California Management Review, 35 (Spring), 82-95.

Louviere, J. J. (1984), “Using Discrete Choice Experiments and Multinomial Logit Choice Models to Forecast Trail in a Competitive Retail Environment: A Fast Food Restaurant Illustration," Journal of Retailing, 60 (4), 81-107.

(1988), Analyzing Decision Making: Metric Conjoint Analysis. Newbury Park, CA: Sage. 
(1994), "Accommodating Ideal Brands and Testing the Predictive Validity of Brand-Anchored Conjoint Analysis," Journal of Retailing and Consumer Services, 1 (1), 21-29.

-, M. F. Fox, andW. L. Moore (1993), “Cross-Task Validity Comparisons of Stated Preference Choice Models," Marketing Letters, 4 (3), 205-14.

--, D. A. Hensher, and J.Swait (forthcoming), "Combining Sources of Preference Data," Journal of Econometrics." (Special issue on "Econometrics and Marketing.")

-, H. Oppewal, H. Timmermans, and T. Thomas (1995), "Handling Large Number of Attributes in Conjoint Analysis: Who Says Existing Techniques Can't Be Applied? But if You Want an Alternative, How about Hierarchical Choice Experiments?" working paper, University of Utah.

---------, J. Swait, and M. Williams (1994), “A Sequential Approach to Exploiting the Combined Strengths of SP and RP Data: Application to Freight Shipper Choice," Transportation, 21, 135-52.

- and H. Timmermans (1990), "Stated Preference and Choice Models Applied to Recreation Research: A Review," Leisure Science, 12, 9-32.

- and G. G. Woodworth (1983), "Design and Analysis of Simulated Consumer Choice or Allocation Experiments: An Approach Based on Aggregate Data," Journal of Marketing Research, 20, 35067.

Lovelock, C. H. (1992), Managing Services: Marketing, Operations, and Human Resources. 2nd ed. Englewood Cliffs, NJ: Prentice Hall.

McFadden, D. (1974), "Conditional Logit Analysis of Quantitative Choice Behaviour," in Frontiers of Econometrics, P. Zarembka, ed. New York: Academic Press.

--------- (1986), “The Choice Theory Approach to Market Research,” Marketing Science, 5 (4), 275-97.

McLean, R. and V. Anderson (1984), Applied Factorial and Fractional Designs. New York: Marcel Dekker.

Moore, W. L., J. Gray-Lee, and J. J. Louviere (1998), “A Cross-Validity Comparison of Conjoint Analysis and Choice Models at Different Levels of Aggregation. Marketing Letters, 9 (2), 195-207.

Oppewal, H., J. J. Louviere, and H.J.P. Timmermans (1994), "Modeling Hierarchical Conjoint Processes with Integrated Choice Experiments," Journal of Marketing Research, 31 (February), 92-105.

Parasuraman, A., V. A. Zeithaml, and L. L. Berry (1985), "A Conceptual Model of Service Quality and Its Implications for Future Research," Journal of Marketing, 49 (Fall), 41-50.

Pullman, M. E. and W. L. Moore (forthcoming), "Optimal Service Design: Integrating Marketing and Operations Elements for Capacity Decisions." International Journal of Service Industry Management.

Rust, R. T., A. J. Zahorik, and T. L. Keiningham (1995), "Return on Quality (ROQ): Making Service Quality Financially Accountable," Journal of Marketing, 59 (April), 58-70.

Sullivan, R. S. (1981), "The Service Sector: Challenges and Imperatives for Research in Operations Management," Journal of Operations Management, 2 (4), 211-14. 
Swait, J. and J. J. Louviere (1993), "The Role of the Scale Parameter in the Estimation and Comparison of Multinomial Logit Models," Journal of Marketing Research, 30 (August), 305-14.

Woodworth, G. G., C. Gilbert, and M. F. Fox (1990), Documentation for the LOGIT Program to Estimate Multinomial Logit Models. Unpublished manuscript, University of lowa, Department of Statistics.

Youngdahl,W. E. and D. L. Kellogg (1997), “The Relationship between Service Customers' Quality Assurance Behaviors, Satisfaction, and Effort: A Cost of Quality Perspective," Journal of Operations Management, 15, 19-32.

Zenor, M. J. and R. K. Srivastava (1993), "Inferring Market Structure with Aggregate Data: A Latent Segment Approach," Journal of Marketing Research, 30 (3), 369-79.

\section{Authors Bio}

Rohit Verma is an assistant professor of operations management in the Department of Management, Kellstadt Graduate School of Business, DePaul University. He also has held visiting appointments at the Helsinki School of Economics and at the University of Sydney. He holds a Ph.D. in operations management, an M.S. in engineering from the University of Utah, and a B.Tech. from the Indian Institute of Technology. His research interests include product/service design, quality and process improvement, quantitative research methods, and business education. His research has appeared in the Cornell Hotel and Restaurant Administration Quarterly, Decision Line, International Journal of Operations and Product Management, International Journal of Service Industry Management, Journal of Hospitality and Tourism Research, Journal of Operations Management, Journal of Product Innovation Management, Omega, Powder Technology, and other publications. Professionally, he has consulted with the First Chicago NBD Corporation and various independent management consulting firms on issues related to product/service design, experimental design, process improvement, and computer simulation.

Gary M. Thompson is an associate professor of operations management in the School of Hotel Administration at Cornell University. He holds a Ph.D. in operations management from Florida State University, an M.B.A. from the University of Western Ontario, and a B.Sc. from the University of New Brunswick. A member of INFORMS, his current research focuses primarily on labor staffing and scheduling. His research has appeared in Computers and Operations Research, Cornell Hotel and Restaurant Administration Quarterly Decision Sciences, Journal of Operations Management, Management Science, Omega, Operations Research, and other publications.

Jordan J. Louviere is a professor in and chair of the Department of Marketing at the University of Sydney. He has taught courses in modeling consumer behavior and consumer information processing and in the relationship of consumer choice behavior to managerial decision making and the objectives of organizations at Florida State University, the University of Wyoming, the University of lowa, the Australian Graduate School of Management, the University of Alberta, the University of Utah, and the University of Sydney. His major research area is the design and analysis of discrete dependent variable experiments and data collection efforts related to understanding and predicting consumer decision making and choice behavior. He has published numerous theoretical, methodological, and empirical articles in scholarly journals on consumer decision making in marketing and transportation planning including the Journal of Consumer Research, Journal of Marketing Research, Marketing Science, Journal of Retailing, Transportation Research, and Journal of Applied Psychology. 